DOI 10.37882/2223-2982.2020.12.40

\title{
НЕКОТОРЫЕ ОСОБЕННОСТИ ХТОНИЧЕСКОЙ СУЩНОСТИ БОГИНИ КИБЕЛЫ В ПРИЧЕРНОМОРСКОМ РЕГИОНЕ В АНТИЧНОЕ ВРЕМЯ
}

\section{SOME FEATURES OF THE CHTHONIC ESSENCE OF THE GODDESS CYBELE IN THE BLACK SEA REGION IN CLASSICAL ANTIQUITY PERIOD}

\section{S. Yartsev \\ E. Shushunova}

Summary: The article looks into the complex topic of the spiritual content of the goddess Cybele's cult in the Black Sea region during the Antiquity period. The main sources of research are ancient images of Cybele. They include special Bosporan terracotta statuettes of the goddess that have regional characteristics. The authors pay special attention to the sacred essence of the lion in the classical iconography of Cybele, as well as some items from the paraphernalia of this image of the goddess. The article considers the direct connection of Cybele with childbirth, as well as the ability of the goddess and accompanying her lion and special objects to resurrect the dead by indicating and sanctifying the way for their souls in the other world and into a new life. The authors of the article come to the conclusion that this cult resembled the religious practice of animating the newborn bodies of babies with souls of deceased ancestors. This was facilitated by the fact that it was during this period in the Antiquity world that ideological transformations intensified. As one of the forms the transformations also manifested themselves in the form of the development of the apotheosis of deceased ancestors.

Keywords: ancient civilization, goddess Cybele, god Attis, lion, fertility cult, chthonic cults, ancestor cult, apotheosis of the dead.
B античное время культ богини Кибелы, был хорошо знаком населению причерноморских поселений и городов. На северных берегах Черного моря, начиная уже $c$ в в. до н.э., судя по граффити на чернолаковой чаше, Кибела почиталась как владычица Гилеи [31, с. 214]. Приблизительно с этого же времени культ богини фиксируется в Тире $[22$, с. 78 , рис. 33, 9-10] Ольвии [19, с. 37; 31 , с. 253], в Херсонесе $[4$, с. 103; 31, с. 275] и на Боспоре [8, с. 224-227; 31, с. 351-352; 26, с. 144-149]. Известен данный культ был также в западных [20, с. 83] и восточных [12, с. 180-179] причерноморских районах античного мира.

По мнению большинства исследователей, изначально Кибела являлась фригийской богиней плодородия, почитание которой восходило еще к древним религиозным представлениям Анатолии эпохи неолита VII-VI тыс.
Ярцев Сергей Владимирович

Д.и.н., доцент, Тульский государственный педагогический университет им. Л.Н. Толстого

s-yartsev@yandex.ru

Шушунова Елена Валерьевна

Аспирант, Тульский государственный педагогический университет им. Л.Н. Толстого schuschunova.elena@yandex.ru

Аннотация: Исследование посвящено сложной теме духовного содержания культа богини Кибелы в причерноморском регионе в античное время. Основными источниками исследования являются древние изображения Кибелы, в том числе особые боспорские терракотовые статуэтки богини, обладающие региональной спецификой. Авторы особое внимание обращают на сакральную сущность льва в классической иконографике Кибелы, а также некоторых предметов из атрибутики данного образа богини. Учитывая прямую связь Кибелы с деторождением, а также способность богини и сопровождающих ее льва и особых предметов воскрешать умерших, указывая и освящая путь их душам в потустороннем мире и в новую жизнь, авторы приходят к выводу, что данный культ напоминал религиозную практику одушевления новорожденных тел младенцев душами умерших предков, известную у других народов. Этому способствовало то, что именно в данный период в античном мире усилились идеологические трансформации, проявившиеся, в том числе и в виде развития апофеоза умерших предков.

Ключевые слова: античная цивилизация, богиня Кибела, бог Аттис, лев, культ плодородия, хтонические культы, культ предков, апофеоз умерших.

до н.э. [3]. При этом культ формировался здесь на основе религиозного синтеза $[28$, с. 220], и в дальнейшем распространялся в соседних Пафлагонии, Каппадокии, Галатии и других регионах Малой Азии [23, с. 224-231]. По всей вероятности, отсюда же, из районов Малой Азии, культ Кибелы проник и в Северное Причерноморье [2, c. 78, 31, с. 353].

В процессе почитания Кибелы, постепенно сложилась устойчивая иконография изображения богини. Считается, что она прошла сложную трансформацию от вида стоящего божества к фигуре богини, сидящей на троне. Вероятно, такие изменения были связаны с довольно удачным образом последней, созданным в конце $V$ в. до н.э. Агоракритом. Греческий скульптор изобразил Кибелу сидящей, в башенной короне, с тимпаном и фиалой в руках и львенком у ног. Именно данный тип, вместе с ука- 
занными атрибутами богини, вскоре стал классическим [23, с. 224; 26, с. 144-149; 16, с. 280-283]. Теперь, если чтото и менялось в нем, например появление в руках плода или птицы (голубя), то объяснялось влиянием образов других греческих богинь Деметры, Коры-Персефоны, Афродиты [23, с. 224]. В таком устоявшемся иконографическом виде Кибела справедливо связывается с культом плодородия [32, с. 321-327], а также с верой в божествозащитника [16, с. 280]. В более широком плане, Кибела представлялась в величественном образе Великой Матери всего сущего - природы, животных растений и т.д. [23, с. 229]. При этом, судя по тому, что из цилиндрической хлебной меры, головной убор богини развился в башенную корону, именно функция божественной защиты, постепенно стала выходить на ведущую роль в ее культе [33, с. 507].

Тем не менее, один из самых устоявшихся и характерных именно для Кибелы атрибутов - лев стоящий или лежащий у ног богини, до сих пор не находит однозначной интерпретации. Однако очевидно, что это животное совершенно не случайно занимало почетное место возле богини. В основе такого сочетания божественного и природного, которое олицетворяло животное, безусловно, лежал глубокий религиозный символизм, смысл которого сейчас чрезвычайно трудно восстановить. Ясным представляется только одно, лев в данном иконографическом образе богини, явно представлял не только силы живой природы. Не случайно лев был связан с почитанием солнечных божеств, такими как Дионис [18, с. 281], Митра, и даже Иао иудейской и каббалистической традиции. Скорее всего, причиной такого духовного родства, являлось то, что данное животное однозначно символизировало солнце [11, с. 216-217; 34, р. 35-36, 136, 150-151]. На примере египетского культа Кибелы, мы знаем, что египтяне украшали «львиными пастями двери храмов, по причине выхода Нила из берегов, «когда впервые солнце встречается со львом»» [Plut. De Is. Et Os., 38]. Похоже, что древние астрологи действительно помещали дом солнца в созвездии льва [29, с. 62], то есть в той части неба, где солнце больше всего пышет жаром. Именно здесь размещалось созвездие, которое ассоциировалось в древности со львом, так как «это животное получает сущность от природы солнца». Объяснялось это превосходством льва над остальными животными «напором и пылом», напоминающим господство солнца среди других звезд [Macr. Sat., I, 21, 16-17].

Такое отношение ко льву, находит свои параллели и в отождествлении царя зверей, как это делал Гомер, с басилеями. Следовательно, лев как символ солнца, также олицетворял царственную силу, власть и связанные с ними благородство и смелость [27, с. 27-29]. С одной стороны, такие верования хорошо сочетаются с древними представлениями, что лев «нужен тем, кто нуждается в защите» [Plut. De Is. Et Os., 19], но с другой стороны, находят свои параллели с подобными же защитными функциями Кибелы. Укрепляет нас в возможности такого отождествления религиозной сущности богини и царственного животного, также и то, что сидящая на троне Кибела, представлялась не просто обожествленной Землей, а богиней верховной власти той земли, на которую власть в данном случае распространялась. Другими словами, Кибела, не только персонифицировала ту или иную землю (город или государство), но и предоставляла, посредством священного брака, право вступления, того или иного, правителя на престол [33, с. 507]. Все это, казалось бы, вполне убедительно свидетельствует о вполне обоснованном вхождении льва в постоянную атрибутику иконографического образа Кибелы, на основе наличия у животного, схожей с богиней функциональной и смысловой нагрузки в виде сакральной защиты людей, олицетворения верховной власти и необходимости ее божественной поддержки.

Тем не менее, не все здесь выглядит так однозначно. Дело в том, что богиня на троне, судя по всему, символизировала не только силу и власть, но и бессмертие [35, s. 28]. В таком случае, если она действительно являлась защитницей мертвых, то львы могли подчеркивать, именно эту хтоническую сущность Кибелы, уходящую своими корнями еще в хетто-вавилонскую эпоху [36, р. 545-553; 23, с. 229]. Такое предположение подтверждается тем, что лев, как у эллинов, так и у варваров, считался животным с амбивалентной семантической нагрузкой, так как он одновременно был связан и с солнцем, и с хтоническим миром [31, с. 242]. Не исключено, что среди прочих атрибутов Кибелы, именно лев обеспечивал, какую-то специфическую связь богини с потусторонним миром, которая явно отличалась от аналогичных контактов в схожих культах. На это непосредственно указывает факт отсутствия льва в обрядовой практике почитания других женских божеств, несмотря на то что хтоническая сущность большинства из них не подвергается сомнению. Связь же Кибелы со львом установилась до того прочная, что изображение богини, сидящей на троне без животного, сразу вызывает сомнения в правильной идентификации божества. Нередко в таких случаях предлагается ассоциация Кибелы, например, с Анаит, Артемидой или Афродитой [23, с. 229], по причине которой, изображение льва становилось уже не нужным. Из этого следует вывод, что хтонические представления связанные с почитанием именно Кибелы, действительно обладали какой-то особой спецификой, не имеющей аналогов в культах других женских божеств.

Мы считаем, что для решения данной проблемы, важно обратить внимание на нестандартные экземпляры статуэток Кибелы, отличающиеся от сложившегося традиционного иконографического образа божества. Так, например, у обнаруженных на Боспоре терракот Кибелы, почему-то исчез лев, зато на груди богини появился 
медальон с Медузой Горгоной, а в руке странный конусовидный предмет. При этом ради размещения последнего, пришлось пожертвовать специальным музыкальным инструментом - тимпаном, который богиня обычно держала в руке в своем классическом иконографическом образе. Самые ранние образцы подобных терракот, датируются III-II вВ. до н.э. и встречаются на многих боспорских городах и поселениях [5, с. 24-28]. Конечно, судя по размещению на груди богини медальона с изображением Медузы Горгоны, мы можем иметь дело, с уже упомянутой нами, ассоциацией Кибелы с другим женским божеством, в данном случае с Афиной, для которой эгида с горгонейноном являлась характерным атрибутом. Однако на Боспоре греческий культ Афины достоверно не был зафиксирован [31, с. 359-361; 5, с. 25], а местное варварское население активно использовало изображение Горгоны уже как своей Великой богини [31, с. 98]. Следовательно, вполне допустимо предположить, что и античное население Боспора могло использовать символизм Медузы Горгоны для подчеркивания, например, каких-то особых черт своего божества. При этом последнее явно имело отношение к подземному миру, так как Горгона настолько ярко хтонична и связана со всеми основными стихиями (солнцем, луной, растительностью, водой, конями) [31, с. 98-99], что не учитывать данный факт просто не представляется возможным. Именно поэтому античное население на Боспоре, скорее всего, использовало указанные выше статуэтки с оригинальной региональной спецификой, для почитания все той же богини Кибелы, но только концентрируя при этом внимание на неких особенных хтонических чертах данного культа.

К схожим выводам приходит А.В. Быковская, анализируя терракоту богини, найденную на Елизаветинском городище в помещении с алтарем, погибшем в огне не позднее 70-х гг. III в. до н.э. Статуэтка представляет собой сидящую на троне богиню с медальоном на груди и башенной короной на голове, в левой руке у которой находится конусообразный предмет, а в правой - фиала. То, что рядом была обнаружена терракота Аттиса - паредра фригийской богини [Polyb., XXII, 20], позволило ученому, справедливо связать данную находку с культом Кибелы [5, с. 26]. Следовательно, если на Боспоре в образе богини с конусообразным предметом в руке, почиталась именно Кибела, то тогда последняя должна была обладать какими-то яркими специфическими чертами, которые, безусловно, нашли свое отражение, как в ритуальном аспекте, так и в восприятии образа божества [5, с. 26-27]. Замена же в иконографии Кибелы, льва на медальон Медузы Горгоны и конусовидный предмет, могла произойти по причине их схожих сакральных функций, что и позволило произвести небольшую трансформацию образа богини. Причиной таких изменений, по-видимому, стала необходимость концентрации внимания на каких-то особых функциях в культе Кибелы, которые основательнее были выражены именно в образах Медузы Горгоны и конусовидном предмете. Все это позволяет с уверенностью предположить, что здесь мы имеем дело с усилением хтонической сущности богини Кибелы. Видимо на каком-то этапе, на ведущее место в религиозной жизни античного населения стали выходить особые взгляды, связанные с потусторонним миром и хорошо представленные именно в культе этой богини. Их символизм и обеспечивал лев, а в некоторых случаях, другие атрибуты Кибелы.

Самым сложным для интерпретации из таких сопровождающих богиню вещей, является указанный конусовидный предмет. А.В. Быковская оригинально связала его с головным убором богини с изображения на пластине из кургана меотской знати IV в. до н.э. - Карагагодеуашх (расположенного вблизи Крымска), а также с курильницами конической формы, обнаруженными на святилище «Полянка» и резиденции Хрисалиска [5, с. 25]. Такое сравнение, вполне возможно, тем более, если учитывать, что все эти предметы, скорее всего, восходят к какому-то первоначальному сакральному изделию, форма которого и послужила образцом и для курильниц и головного убора божества. По нашему мнению, данный культовый предмет хорошо известен и часто использовался в виде отдельных конусовидных пирамидок, обычно производимых из мела, так как им необходимо было придать белый цвет. Считается, что данные культовые предметы были более характерны для сарматских женских погребений [6, с. 139], однако встречаются и на античных поселениях Северного Причерноморья. Возможно, что обращению к указанным сакральным изделиям в ходе трансформации образа Кибелы, способствовало усилившееся в данное время сарматское воздействие на население Боспорского царства. Тем более что обратное влияние культа Кибелы на верования варварских племен Северного Причерноморья, также прослеживается [28, с. 218-224]. Однако даже если учитывать сарматское влияние, необходимо помнить, что собственно конус и в частности, конические камни, всегда являлись символом плодородия в восточных и средиземноморских религиях древности [17, с. 203]. По-видимому, отсюда происходят и древние представления о треугольнике, который у многих народов отождествлялся с женским полом и являлся символом Великой богини [1, с. 18], как правило, с сильно выраженными хтоническими чертами [7, с. 83-85]. Кроме того, предметы подобной формы также способствовали деторождению. Именно поэтому их часто использовали в соответствующих ритуалах, применяя даже в качестве элемента одежды [30, с. 30].

Белый же цвет конусовидных пирамидок, по нашему мнению, также не случаен. Его смысловая нагрузка хорошо прослеживается по нартскому эпосу, в основе которого, как известно, лежат древние предания скифо-сарматских племен. Так, обращает внимание, что 
свечение «как солнце», и сияние «как луна» матери Нартов, означало ее появление в «ином» царстве, как бы освещение ею потустороннего мира [9, с. 100]. Более того, в нартских сказаниях нередко молодые девушки, к которым сватаются герои эпоса, излучают особый свет [9, с. 102-103,111-112]. В одном же из сюжетов сошествия героя в потусторонний мир, при возвращении его из похода темной ночью, именно жена должна была освящать мужу путь домой. Стоило ей из-за ссоры, не освятить ему дорогу при перегоне табуна через мост, как герой вместе с лошадьми сорвался и упал в бушующий поток [9, с. 153].

Все вышесказанное, и в первую очередь, взаимосвязь конических пирамидок с культом плодородия, деторождением и потусторонним миром, по нашему мнению, свидетельствует о главной хтонической функции богини, достигаемой с помощью данных предметов - уравновешиванию преждевременной смерти, посредством появления новой жизни. Видимо, лев и другие предметы из иконографического образа Кибелы, должны были обеспечивать подобную связь божества с потусторонним миром, способствуя воскресению и рождению ребенка. Любопытно, но именно такую особенность льва, по-видимому, хорошо осознавали в древности. В сочинении «Физиолог» II - IV вв. н.э., в котором было собрано большинство античных сведений о чудесных свойствах животных, несмотря на возможные поздние исправления [24, с. 131, прим. 26], содержится достаточно оригинальная информация о льве, помогающая раскрыть сакральную сущность этого животного. Внимание здесь концентрируется на трех особых свойствах льва, на его таланте заметать следы от охотников, умении спать с открытыми глазами и способности воскрешать умершего детеныша. Последнего вначале рожала львица, после чего на третий день приходил отец и подув ему в лицо, пробуждал его [24, с. 131]. В этой связи, нет ничего удивительного, что в христианстве лев стал символизировать Воскресение [18, с. 281], или даже самого Иисуса Христа, если верно были интерпретированы изображения животного на амулетах [29, с. 65-66]. В любом случае, в тексте «Физиолог», лев однозначно связывался с Иисусом. Заметающий следы лев, символизировал здесь Христа, скрывавшего свою Божественность. Лев умеющий спать с открытыми глазами, отождествлялся с Иисусом физически мертвым после распятия, но духовно живым своей Божественной природой. Лев же, оживляющий мертвого львенка, представлялся Богом Отцом, воскрешающим Иисуса из мертвых [24, с. 131]. Связь Воскресения с образом льва прослеживается и в ряде других поздних сочинений позднеантичных и средневековых авторов $[18$, с. 281].

Надо сказать, что и образ самой Кибелы, не в меньшей степени, свидетельствует о достаточно противоречивых взаимоотношениях богини с потусторонним миром. С одной стороны, богиня действительно являлась защитницей мертвых, что подтверждает, в том числе и зафиксированная надпись на ее статуэтке «памяти ради» [23, с. 228]. Однако, с другой стороны, именно ей, как Матери богов нередко делали посвящение за детей, а саму ее изображали с одной рукой на груди, а с другой на животе, что самым непосредственным образом символизировало воспроизводящие силы природы [23, с. 226-227]. Даже подробности мистерий в честь Кибелы, на которых разыгрывались сцены гибели и возрождения ее возлюбленного Аттиса [25, с. 107], безусловно, также свидетельствуют о сложных верованиях, связанных с бессмертием души в культе данного божества [14, с. 91]. Особенно важным здесь представляется то, что возрождение богиней умершего Аттиса, давало людям надежду после смерти на воскресение в другой жизни [25, с. 107-108]. Следовательно, у людей, у которых умерли, особенно преждевременно, ближайшие родственники, появлялась возможность обеспечить связь поколений и восстановить нарушенное смертью равновесие. Именно в этом им должна была помочь Кибела, которая в своем классическом иконографическом образе вместе со всеми своими атрибутами, включая льва, как раз и обеспечивала такую важную для людей божественную поддержку в тяжелые для них времена.

Таким образом, учитывая прямую связь Кибелы с деторождением, а также способность богини и сопровождающих ее льва и особых предметов воскрешать умерших, указывая и освящая путь их душам в потустороннем мире и в новую жизнь, можно допустить, что данный культ напоминал религиозную практику одушевления новорожденных тел младенцев душами умерших предков, известную у других народов [13, с. 36]. Может быть, именно благодаря развитию таких представлений, происходил неуклонный рост популярности культа Кибелы в эллинистический период [16, с. 280] и особенно в первые века нашей эры [26, с. 147-149]. Безусловно, этому способствовало то, что именно в данный период в античном мире усилились идеологические трансформации, проявившиеся, в том числе и в виде развития апофеоза умерших предков. Теперь каждый из таких родственников, в идеале мог достичь бессмертия и превратиться в героя (сына бога и смертной), что фактически отождествляло его с божеством [15, с. 38; 21, с. 381-385; 10, с. 58-81]. Логично, когда в этой ситуации, учитывая особые свойства Кибелы, душу предка стремились вернуть в мир живых, пытаясь одушевить ею новорожденных и достичь тем самым реального, по своим понятиям, бессмертия. На такую возможность явно указывает способность льва не просто воскресить мертвого львенка, но и вдохнуть в него чужую душу или даже отчасти отдать свою, что фактически означает передачу ее от ближайшего предка детеныша. Однако отметим, что лев здесь явно выступает в качестве божества, с которым, как известно, и отождествляется умерший предок в 
процессе его апофеоза. Поэтому, то обстоятельство, что после оживления детеныша лев остается живым, может указывать не на свою, а на чужую душу, используемую божественной силой в качестве источника воскресения. В ситуации религиозных трансформаций, очевидно, что такой душой может быть только душа предка. Учитывая, что лев занимал прочную позицию возле Кибелы и, скорее всего, полностью ассоциировался с ней, вероятно именно богиня и являлась тем божеством, которое посредством одушевления душами предков новых жизней, восстанавливало нарушенное смертью мировое равновесие. Заметим, что все это хорошо сочеталось с сакральными свойствами конусовидных предметов, повидимому, помогающих освещать дорогу и находить в потустороннем мире богиню Кибелу, а также облегчать путь душам в мир живых.

Наши выводы подтверждают и наметившиеся новые тенденции в иконографии образа богини в первые века нашей эры. Так в это время, как в центрах греко-римского мира, так и на периферии (например, на Боспоре) получает распространение особый иконографический мотив Кибелы, в котором богиня изображается вместе с другими богами или их атрибутами. Здесь особый интерес вызывает то, что данными божествами являлись Гермес и Геката, отвечающие за границы зоны перехода и поэтому обладающие редкой способностью перемещаться между двумя мирами. В этой связи действительно уместно будет вспомнить о важной роли указанных богов, в возвращении Коры Персефоны из Аида на землю к своей матери Деметре [26, с. 148-149]. Такая особенность обновленного иконографического образа Кибелы, вполне соответствует нашим выводам о специфике религиозных представлений, связанных с почитанием данного божества.

\section{ЛИТЕРАТУРА}

1. Амброз А.К. Раннеземледельческий культовый символ («ромб с крючками») // СА. 1965. №3. С. 14-27.

2. Бабинов Ю.А. Посвятительные граффити из Херсонеса Таврического // ВДИ. 1970. №4. С. 73-80.

3. Богатова 0.В. Культ Великой Матери богов Кибелы в греко-римской древности (к проблеме религиозного синкретизма в античности): автореф. дис.... к. ист. н. СПб., 1998. 25 С.

4. Бондаренко М.Е. Пантеон Херсонеса Таврического. М.: Компания Спутник, 2003. 169 с.

5. Быковская А.В. Культ Кибелы на Боспоре: отдельные вопросы // Таврические студии. 2018. № 16. С. 24-28.

6. Габуев Т.А., Малашев В.Ю. Памятники ранних алан центральных районов Северного Кавказа. М.: Таус, 2009. 468 с.

7. Голан А. Миф и символ. М.: Русслит; Иерусалим: Тарбут, 1993. 371 с.

8. Горончаровский В.А. К вопросу о культе Кибелы на Боспоре в первые века н.э. // Stratum plus. 1999. № 3. С. 224-227.

9. Джапуа 3.Д. Абхазский нартский эпос: Текстология. Семантика. Поэтика. М.: Наука; Восточная лит-ра, 2016. 381 с.

10. Диатроптов П.Д. Культ героев в античном Северном Причерноморье. М.: «Индрик», 2001. 160 с.

11. Кагаров Е.Г. Культ фетишей, растений и животных в Древней Греции. СПб.: Сенатская типография, 1913. 326 с.

12. Капанадзе Д.Г. Археологические находки Пицундской археологической экспедиции за 1953-1959 гг. // ВДИ. 1966. №4. С.173-179.

13. Косарев М.Ф. Мировоззренческие аспекты традиционной погребальной обрядности (по сибирским материалам) // КСИА. 2010. Вып. 224. С. $33-51$.

14. Кюмон Ф. Восточные религии в римском язычестве. СПб.: Изд-во «Евразия», 2017. 352 с.

15. Масленников А.А. Некоторые особенности некрополей городов Европейского Боспора первых веков н.э. // СА. 1982. №1. С. $33-43$.

16. Нессель В.А. Новые данные о культе Кибелы в Херсонесе в первые века н.э. // Сугдейский сборник. Киев; Судак: Академпериодика, 2004. Вып. І. C. $280-283$.

17. Носова Л.В. Греческие культы на западной окраине ольвийского полиса // Боспорский феномен: Проблема соотношения письменных и археологических источников. СПб.: Изд-во Гос. Эрмитажа, 2005. С. 201-206.

18. Ошарина 0.В. Изображение льва в коптском искусстве // Вестник Санкт-Петербургского университета. 2007. Сер. 2. Вып. 4. С. $281-286$.

19. Русяєва А.С. Культ Кібели в Ольвії // Археологія. 1972. Вып. 7. С. 35-45.

20. Русяева А.С. Античные терракоты Северо-Западного Причерноморья (VI-I вв. до н.э.). Киев: Наукова думка, 1982. 165 C.

21. Русяева А.С., Зубарь В.М. Религиозное мировоззрение // Херсонес Таврический в середине I в. до н.э. — VI В. н.э.: Очерки истории и культуры. - Харьков: «Майдан», 2004. - С. 333-430.

22. Самойлова Т.Л. Тира в VI-I вВ. до н.э. Киев: Наукова Думка, 1988. 120 с.

23. Сапрыкин С.Ю. Религия и культы Понта эллинистического и римского времени. М.; Тула: Гриф и К, 2009. 426 с.

24. Сафронова Н.В. Жанр бестиария между Востоком и Западом // Востоковедение: История и методология. 2019. Вып.І. С. 125-135.

25. Скржинская М.В. Древнегреческие праздники в Элладе и в Северном Причерноморье. Киев: НАН Украины, 2009. 365 с.

26. Толстиков В.П., Муратова М.Б. 0 некоторых особенностях культа Кибелы в Пантикапее в первые века н.э. в свете новейших археологических исследований // Таврические студии. 2017. № 12. С. 144-149.

27. Туманс Х. «Львы» и «волки» у Гомера: заметки к эпической «табели о рангах» // Аристей. 2011. №4. С. $27-51$.

28. Фидельский С.О культе Кибелы в Нижнем Поднестровье (по материалам раскопок многослойного поселения Чобручи) // 
29. Емінак: наук. журн. / Н.-д. центр «Лукомор'є» Ін-ту археології НАН України. Миколаїв, 2016. № 4. С. 218-224.

30. Хайрединова Э.А. Византийские цельнолитые пряжки-апотропеи второй половины VII в. из Крыма // Античная древность и средние века. 2016. Вып. 44. C. $60-86$.

31. Хоружая М.В. «Рогатые» пряжки в знаковой системе салтовского населения бассейна Северского Донца // Вісник Харківського національного університету імені В.Н.Каразіна. Історія. 2009. №852. С. 28-42.

32. Шауб И.Ю. Миф, культ, ритуал в Северном Причерноморье (VII-IV вВ. до н.э.). СПб.: Изд-во СПбГУ, 2007. 484 с.

33. Элиаде М. История веры и религиозных идей: от Гаутамы Будды до триумфа христианства. М.: Академический Проект, 2012. 676 с.

34. Ярцев С.В. Некоторые вопросы сакральной защиты городища Белинское в позднеантичный период // Древнее Причерноморье. Одесса: ФЛП «Фридман А.С.», 2011. Вып. IX. C. 505-511.

35. Bonner C. Studies in Magical Amulets, chiefly Graeco-Egyptian. Ann Arbor: University of Michigan Press (London: Geoffrey Cumberlege), 1950.334 p.

36. Jung H. Thronende und sitzende Götter. Zum griechischen Menschenideal in geometrischer und früharchaischer Zeit / Habelts Dissertationsdrucke. Reihe Klassische Archäologie, 17. Bonn: Habelt, 1982. 375 s.

37. Reinach S. Statues archaïques de Cybèle découvertes à Cymè (Éolide) // Bulletin de Correspondance Hellénique. 1889. V. 13. P. 543-562. ( ) Ярцев Сергей Владимирович (s-yartsev@yandex.ru), Шушунова Елена Валерьевна (schuschunova.elena@yandex.ru)

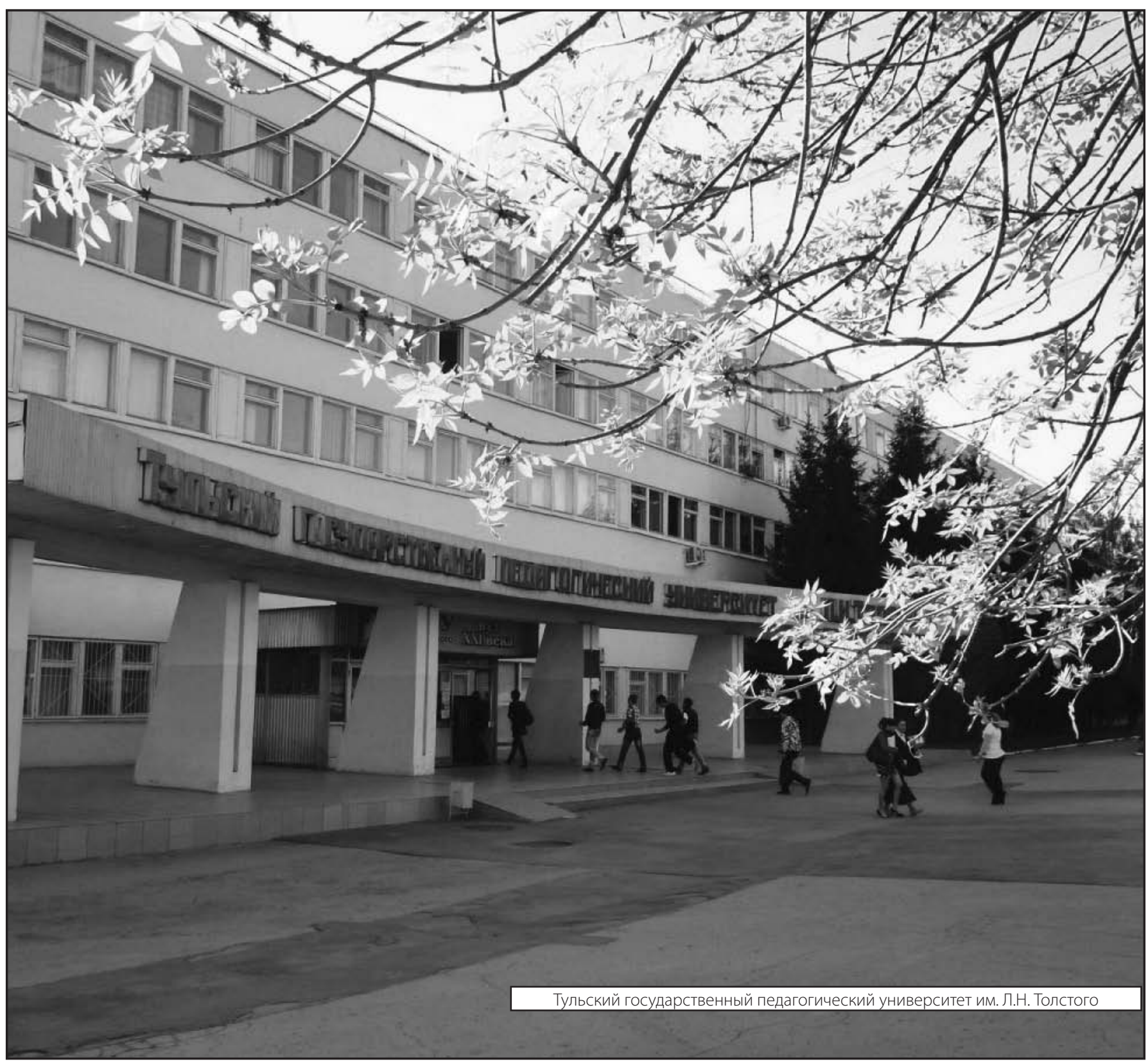

